\title{
Formação continuada de educadores e as tecnologias digitais da informação e da comunicação em escolas de governo: conceitos e práticas do Estado de São Paulo
}

\author{
Ana Panzani Alves ${ }^{1}$ \\ Orientadora Profa. Dra. Maria da Graça Moreira da Silva ${ }^{1}$ \\ ${ }^{1}$ Programa de Estudos Pós-graduados em Educação: Currículo - Pontifícia \\ Universidade Católica de São Paulo - São Paulo - SP - Brasil

\begin{abstract}
This article is about federal and state public policies of continued teachers training and how is the use of Information and Communication Technologies in the context of governmental school Escola de Formação e Aperfeiçoamento dos Professores do Estado de São Paulo "Paulo Renato Costa Souza" of State of São Paulo's education department. For the analysis, were collected documentary evidence of 125 training teachers sessions offered by EFAP, between 2009 and 2013. The study indicates similarities between the practices of this governmental school and public educational policies and promoting appropriation of technologies by educators and carrying out actions that focus on training in context.
\end{abstract}

Resumo. Este artigo versa sobre as políticas públicas nacionais de formação continuada de educadores e o papel e uso das tecnologias digitais da informação e da comunicação. Analisa o caso da Escola de Formação e Aperfeiçoamento dos Professores do Estado de São Paulo "Paulo Renato Costa Souza" da Secretaria da Educação do Estado de São Paulo. Para a análise, foram coletados os dados documentais de 125 ações de formação ofertadas pela EFAP, entre 2009 e 2013. O estudo indica convergências entre as práticas desta escola de governo e as politicas públicas educacionais, bem como a promoção da apropriação das tecnologias pelos educadores e a realização de ações que privilegiam a formação no contexto.

\section{A formação de professores no contexto da escola republicana brasileira}

Este artigo versa sobre a formação continuada de educadores no contexto da Escola de Formação e Aperfeiçoamento dos Professores do Estado de São Paulo "Paulo Renato Costa Souza" (EFAP), escola de governo da Secretaria da Educação do Estado de São Paulo (SEE-SP), envolvendo a formação continuada de educadores como um dos cernes do processo de democratização do acesso à escola pública e, então, de garantia dos direitos à educação com qualidade social. Nesse estudo, advindo de dissertação de mestrado defendida em 2014 [Panzani 2014], têm destaque os debates e a promulgação de políticas públicas educacionais relacionadas à formação continuada de educadores, bem como o papel das Tecnologias Digitais da Informação e da Comunicação (TDIC) tanto para a realização das ações de formação continuada no Estado de São Paulo, quanto em relação às TDIC enquanto aparato tecnológico humano a ser apropriado por educadores e educandos. 
Este artigo objetiva identificar a convergência entre as políticas públicas de formação continuada de educadores e as ações de formação continuada ofertadas pela EFAP no período de 2009 e 2013, bem como o papel das TDIC nessas ações e os principais achados desse estudo. Para subsidiar esta reflexão, será apresentado um breve cenário do contexto educacional brasileiro dos últimos 30 anos, com ênfase nas políticas públicas de formação continuada de educadores vigentes e o papel das TDIC enquanto meio para a realização de ações de formação continuada e, principalmente, com vistas à emancipação digital.

\section{Formação continuada de educadores e o desafio do Estado de São Paulo}

A partir da década de 1990, a educação brasileira tem passado por muitas mudanças: a promulgação da Lei de Diretrizes e Bases (LDB), nº 9.394, de 1996 [Brasil 1996], que estabelece a obrigatoriedade de formação dos professores da educação básica em nível superior, redefiniu os rumos das atuais políticas públicas voltadas para a educação e reflete, inclusive, um período de debates sobre a questão da importância da formação continuada; a criação do Fundo de Manutenção e Desenvolvimento do Ensino Fundamental e da Valorização do Magistério (Fundef) e, posteriormente, como forma de aprimorar e ampliar a distribuição e a aplicação dos recursos, a consolidação do Fundo de Manutenção e Desenvolvimento da Educação Básica e de Valorização dos Profissionais da Educação (Fundeb), em substituição ao Fundef.

$\mathrm{Na}$ década de 2000, destacam-se as Diretrizes Curriculares Nacionais para a Formação de Professores, promulgadas em 2002, e, nos anos seguintes, a aprovação pelo Conselho Nacional de Educação das Diretrizes Curriculares para cada curso de licenciatura. Em 2009, foi instituída, pelo Decreto $n^{\circ}$ 6.755, de 2009, a Política Nacional de Formação de Profissionais do Magistério da Educação Básica.

É relevante destacar que o Decreto $n^{0} 6.755$ [Brasil 2009] procura organizar, em regime de cooperação entre os níveis de governo da União, dos estados e municípios, a oferta de formação inicial e continuada do magistério para as redes públicas da educação básica. No que se refere à formação continuada, é necessário garantir sua articulação com a formação inicial, seu caráter de componente essencial de profissionalização docente e o imperativo de integrar-se ao cotidiano da escola. Para tanto, devem ser considerados os saberes e a experiência docente, reforçando a formação continuada como prática escolar regular que responda às características culturais e sociais regionais [Gatti e Barreto 2009]. Esse decreto dispõe, ainda, em seu Artigo $3^{\circ}$, incisos II e III, que a oferta e a expansão de cursos de formação inicial e continuada a profissionais do magistério se dará pelas instituições públicas de Educação Superior, bem como serão equalizadas, em nível nacional, as oportunidades de formação inicial e continuada dos profissionais do magistério [Brasil 2009]. Vale ressaltar que este decreto, centrado no desenvolvimento de competências pessoais, sociais e profissionais necessárias à educação básica, destaca alguns princípios norteadores do preparo para o exercício profissional da docência, tais como: considerar, de um lado, a formação de competências necessárias à atuação profissional, como foco do curso, a coerência entre a formação oferecida e a prática esperada do futuro educador, e, de outro, a pesquisa, voltada para o ensino e a aprendizagem, para compreensão do processo de construção do conhecimento. 
Indo ao encontro dessa questão, no Plano Nacional de Educação (PNE), aprovado em 2014, [Brasil 2014] aproximadamente 20\% das metas têm relação direta com a valorização e com a formação dos profissionais do magistério. Desse modo, a formação continuada deve estar articulada à carreira do magistério e integrar-se ao cotidiano da escola [Davis 2011]. Nesse contexto, as secretarias de educação compreenderam que a formação continuada poderia visar e propiciar um melhor desempenho dos profissionais em exercício nas redes públicas de ensino no que se refere à qualidade da educação e, então, da aprendizagem dos alunos.

Relevante também destacar que a redemocratização da educação pública implicou um desequilíbrio entre a ampliação da oferta de vagas e a capacidade das instituições escolares de atender aos alunos em conformidade com o esperado, visando à qualidade da educação a todos. Na medida em que os sistemas escolares não mais conseguiram enfrentar os desafios postos, as condições de trabalho foram também piorando sensivelmente. Assim, as reformas educacionais foram acompanhadas, também, de desafios para as instituições responsáveis pela formação inicial e continuada dos profissionais da educação. Gatti e Barreto (2009) indicam que decorre daí, em parte, o desenvolvimento intenso de programas de educação continuada com o objetivo de prover formação para implantação de reformas educativas e enfatizam que os processos de formação continuada desenvolvidos desde os anos 1980 querem para atualização ou complementação de conhecimentos, quer para preparar a implementação de uma reforma educativa, não produziram os efeitos esperados e muitas são as razões levantadas nesse cenário, tais como: a dificuldade da formação em massa, a brevidade dos cursos e a dificuldade de fornecer os instrumentos e o apoio necessários para a realização das mudanças esperadas.

Observa-se, ainda, a limitada, senão ausente, participação dos educadores na definição de políticas de formação docente, como categoria profissional, e na formulação de projetos de formação que têm a escola e o seu fazer pedagógico como lócus. $\mathrm{O}$ fazer docente está intimamente relacionado às transformações do mundo do trabalho e de sua prática educativa, bem como considera seus contextos social, político, econômico, sua cultura e seus valores filosóficos e de compreensão de sua prática. Assim, faz-se necessário considerar a formação continuada de educadores como um dos eixos de sua prática, conciliada e envolta em sua trajetória, nas suas reflexões, nos seus anseios.

Nesse sentido, secretarias municipais, estaduais e o Ministério da Educação fomentam e ofertam ações de formação continuada a educadores. No âmbito do Estado de São Paulo, foi criada, conforme Decreto $\mathrm{n}^{0}$ 54.297, de 2009, a EFAP, a escola de governo da SEE-SP, que passa a ser responsável por gerenciar, coordenar e ofertar as ações de formação de seus profissionais [São Paulo 2009]. A EFAP tem como um de seus desafios formar um grande contingente de profissionais de educação, cerca de 240 mil, segundo dados disponíveis em seu sítio em 2014, distribuídos geograficamente pelos municípios do estado de São Paulo, o que demanda o esforço logístico de formação em larga escala e o faz por meio das TDIC. Para tanto, mescla atividades presenciais e a distância, usa ferramentas tecnológicas e estratégias pedagógicas nessas modalidades. 


\section{Formação continuada de educadores e TDIC}

Para alguns autores da literatura recente [Tedesco 2012], as TDIC têm aspectos potencialmente democratizantes, entre eles: acesso a materiais de alta qualidade por meio de sítios remotos; promover a aprendizagem independentemente da localização física dos sujeitos, com interação e propostas de aprendizagem flexíveis; possibilidade de incrementar os níveis educacionais devido a mudanças de processos e estratégias didáticas, promoção de experiências de aprendizagem mais criativas e diversas; possibilidade de promoção de uma aprendizagem independente e permanente de acordo com as necessidades do sujeito.

No entanto, tais potencialidades estão longe de ser realidade, já que não dependem das próprias TDIC, mas de modelos sociais e pedagógicos nos quais são utilizadas. Desse modo, é de fundamental importância colocar as estratégias de incorporação das TDIC aplicadas à educação no marco de uma "política educacional sistêmica dirigida a reduzir as desigualdades e a romper o determinismo social dos resultados de aprendizagem" [Tedesco 2012], incorporando-as às políticas democráticas educacionais, não só pelas potencialidades das novas tecnologias do ponto de vista cognitivo, mas, sim, devido ao fato de o desenvolvimento e a aplicação das TDIC produzirem um fenômeno de acumulação de conhecimentos nos circuitos criados por meio delas, podendo condenar à marginalidade todos os que fiquem fora do domínio dos códigos que permitam manejar essas tecnologias.

Anteriormente ao atual cenário, Almeida (2009) retoma que Paulo Freire já indicava a necessidade de se resgatarem as potencialidades das tecnologias para as escolas, pelo questionamento, pela democratização, pela emancipação digital originada do uso político das técnicas. Para tanto, faz-se necessário que o educador se aproprie das TDIC enquanto sujeito social e, então, as integre em sua prática pedagógica.

Almeida e Costa (2011) indicam a importância de considerar três dimensões ao planejar e implementar ações de formação de servidores da educação: a política, a pedagógica e a tecnológica, e indicam que os cursos na modalidade a distância vão propiciar - não em si, mas atrelados a um coerente e rico projeto pedagógico de formação - uma formação massiva, sem dispersão de tempo e com qualidade social.

As TDIC, além de direito humano, são ferramentas essenciais à formação de educadores, já que possibilitam ações no contexto da prática do professor, bem como democratizam o acesso dos educadores a ações de formação antes multiplicadas localmente por representantes dos sistemas de ensino de modo centralizado. No contexto da cultura digital, as TDIC proporcionam novas sociabilidades, práticas sociais inéditas e construção identitária dos educandos e educadores. Assim, neste artigo, defende-se o papel das TDIC como aliadas para a formação dos servidores da educação. A seguir é explicitado o percurso metodológico percorrido neste estudo.

\section{Percurso metodológico}

Este estudo é caracterizado como análise documental, de natureza qualitativa. Com base no panorama das ações ofertadas pela EFAP entre 2009 e 2013, procedeu-se a análise desses dados relacionados às políticas públicas de formação continuada de educadores. 
Foram coletados e analisados os dados gerenciais de 125 ações de formação continuada ofertadas pela EFAP desde sua criação, em 2009, até o ano de 2013, conforme relação disponível no sítio da EFAP em maio de 2014. Neste estudo, emergiram e foram consideradas as seguintes categorias de análise: Ano de oferta; Público-alvo; Oferta de vagas; Objetivos; Carga horária; Tipo (extensão/atualização/aperfeiçoamento, formação de tutores, pós-graduação, curso para ingressantes); Modalidade; Evolução funcional; Parcerias com universidades; Como se dá o uso das TDIC.

Com base nesses dados, foi possível traçar uma série de convergências dessas práticas em relação às políticas públicas voltadas para a formação continuada de educadores, respondendo à problemática deste trabalho, bem como o uso intensivo das TDIC. A seguir, são destacadas as principais convergências analisadas.

\section{Apresentação da análise dos dados}

\subsection{Teoria, prática e a carreira do educador}

Na LDB [Brasil 1996], Título VI, há a indicação de que a formação dos profissionais da educação deverá ser realizada associando teoria e prática e com capacitação em serviço. No PNE, de modo transversal, é destacada a promoção da formação continuada de educadores de todos os níveis da educação básica, bem como que as ações de formação articulem teoria e propostas pedagógicas à prática dos educadores. No Decreto $\mathrm{n}^{\circ} 6.755$ [Brasil 2009], a formação continuada é entendida como essencial para a profissionalização docente, devendo ser integrada ao cotidiano da escola e tendo de considerar os diferentes saberes e práticas dos educadores, estimulando o ingresso, a permanência e a progressão na carreira de educador. Nas políticas que regem a EFAP, é definido que essa escola é a responsável por ofertar ações de formação continuada (atualização, aperfeiçoamento, especialização) a todos os servidores da SEE-SP, inclusive os provenientes de concursos de ingresso.

A análise dos dados coletados evidenciou aderência da prática da EFAP em relação a essas políticas, considerando que as ações privilegiam, conforme disposto em seus objetivos, a articulação da teoria e prática, bem como a oferta de ações de formação tanto de atualização e aperfeiçoamento, quanto de pós-graduação. Além disso, destacam-se as ações de formação voltadas para os ingressantes na carreira docente na SEE-SP e, também, o fato de 88,8\% das ações de formação ofertadas entre 2009 e 2013 serem válidas para evolução funcional.

\subsection{TDIC}

A análise documental das políticas públicas que compuseram este estudo no que se refere às TDIC, apontou que: na LDB [Brasil 1996], Título VI, no Decreto $\mathrm{n}^{\circ} 6.755$, Artigo $8^{\circ}$ [Brasil 2009], no Decreto 54.297 [São Paulo 2009] e no Decreto $n^{\circ} 56.460$ [São Paulo 2010], destaca-se que a formação continuada dos educadores poderá utilizar TDIC e poderá ser realizada presencialmente ou a distância. No PNE [Brasil 2014], nas metas 5, 7 e 14, por exemplo, há a indicação de que as TDIC têm de ser trabalhadas nas formações inicial e continuada dos educadores de modo que tenham conhecimento de novas tecnologias educacionais e práticas pedagógicas inovadoras. Já na Meta 7 do PNE, há, também, algumas estratégias voltadas para as TDIC, com destaque para: 
universalizar o acesso à rede mundial de computadores em banda larga; prover recursos tecnológicos para utilização pedagógica nas escolas; e informatizar por completo a gestão das redes públicas.

No Decreto $n^{0} 6.755$ [Brasil 2009], Artigo $3^{\circ}$, há destaque para que a formação dos educadores promova a atualização técnico-metodológica dos profissionais da educação inclusive no que se refere ao uso das TDIC nos processos educativos. No Currículo do Estado de São Paulo [São Paulo 2010], há o destaque para que as tecnologias não sejam caracterizadas como fator de exclusão, havendo a necessidade de que todos se apropriem desse aparato cultural e cabendo à escola preparar os educandos para viver em uma sociedade da informação, considerando-se, para tanto, a promoção da alfabetização tecnológica.

Em paralelo, nos documentos que regem a EFAP, as TDIC são destacadas em vários excertos, dentre eles: no Decreto n ${ }^{0} 55.717$ [São Paulo 2010], a definição de que a EFAP deve disponibilizar infraestrutura e tecnologias de ensino presencial e a distância para as ações de formação; deve planejar e coordenar estudos, pesquisas, criação e produção de programas de educação a distância, bem como gerir a infraestrutura e demais recursos tecnológicos; no Decreto n ${ }^{0} 56.460$ [São Paulo 2010] há a definição de que a EFAP deve, enquanto uma de suas diretrizes constitutivas, incentivar o uso das TDIC como suporte ao processo de ensino e de aprendizagem.

Esse é mais um ponto de convergência entre as políticas públicas e os conceitos e práticas da EFAP de 2009 a 2013. Das 125 ações de formação consideradas neste estudo, foi identificado o uso de TDIC em 123, perpassando o uso das tecnologias: de modo informacional, como suporte técnico e ou de gestão da ação, bem como meio para realização dos cursos. Em sete ações as TDIC foram identificadas enquanto objetivo de determinada ação e para que sejam incorporadas à prática pedagógica. Caracterizando a EFAP como uma referência quanto ao uso das TDIC nas ações de formação e, também, promovendo o acesso e a apropriação das TDIC por parte dos educadores para sua prática.

\subsection{Pós-graduação e parcerias com instituições de ensino superior}

No PNE [Brasil 2014], nas metas 1, 14, 16, 18, e nos artigos $3^{\circ}$ e $8^{\circ}$ do Decreto $n^{\circ} 6.755$ [Brasil 2009], há a ênfase para a promoção de ações de formação continuada em nível de pós-graduação, bem como a oferta de ações por parte de instituições públicas de ensino superior, de forma orgânica e articulada às políticas publicadas de formação continuada. Nos decretos de criação e de regulamentação da EFAP, é disposto que a EFAP poderá celebrar convênios com as universidades públicas e privadas para a oferta das ações de formação. Neste estudo, foram identificadas 33 ações ofertadas realizadas pela EFAP em parceria com universidades públicas e privadas, totalizando pouco mais de $26 \%$ das ações ofertadas entre 2009 e 2013, ratificando a relevância da parceria da EFAP com universidades para a realização de ações de formação em nível de pósgraduação.

\subsection{Gestores escolares}

Na Meta 19 do PNE [Brasil 2014] e no Decreto no 55.717 [São Paulo 2010], há destaque para o desenvolvimento de formação de diretores e gestores escolares. No 
Currículo do Estado de São Paulo [São Paulo 2010], é apresentado o conceito da escola que aprende, com ênfase na necessidade de estabelecimento de uma comunidade aprendente, a responsabilidade da equipe gestora como formadora de professores e a responsabilidade dos docentes, entre si e com o grupo gestor, na problematização e na significação dos conhecimentos sobre sua prática. Conforme análise dos dados coletados, das 125 ações de formação ofertadas, pôde-se identificar que, além das ações de formação direcionadas a todo ou a parte do quadro do magistério, incluídos os gestores, 12 ações, aproximadamente 10\%, foram direcionadas exclusivamente a gestores escolares e relacionadas à sua prática, enfatizando a oferta de ações a esse público.

Além desses pontos, é relevante destacar que nos decretos de regulamentação da EFAP, há a definição de que esta escola deverá ofertar ações de formação para ingressantes, cursos de aperfeiçoamento, de atualização e de especialização e cursos complementares de educação continuada, convergindo, assim, às definições e diretrizes presentes nas políticas públicas que respaldam seus conceitos e sua prática.

Com vistas a recuperar os aspectos que sobressaíram do conjunto de dados analisados, serão apresentadas a seguir as possíveis contribuições dos achados desse estudo ao campo da formação continuada de educadores por meio de escolas de governos e o uso de TDIC nessas ações.

\section{Considerações}

Neste estudo, pôde-se identificar que a EFAP é uma escola de governo que coloca em prática as políticas públicas de formação continuada de educadores: implementa ações de formação de extensão, aperfeiçoamento e pós-graduação; promove ações direcionadas a todos os seus quadros funcionais, inclusive os ingressantes; faz uso das TDIC para atingir os mais de 240 mil profissionais distribuídos em todo o estado; realiza ações presencias e a distância, privilegiando aquelas que relacionem a teoria e a prática. Assim, o estudo sugere que os conceitos e práticas da EFAP são correspondentes e convergentes às políticas nacionais de formação de educadores e às que regulamentam a EFAP. Na prática, emprega as TDIC como meio para realização das ações de formação e promove, também, a apropriação das TDIC pelos educadores, tanto enquanto cursistas quanto voltada à prática pedagógica dos educadores.

No entanto, a título de contribuição, os dados disponibilizadas no sítio da EFAP, embora numerosos, poderiam oferecer informações adicionais sobre a oferta das ações de formação, conforme descrito a seguir.

\subsection{Planejamento da oferta de formação continuada}

Ao pesquisar o sítio da EFAP, não foi localizada explicitamente a definição de formação continuada para essa escola de governo, assim como não foi localizado o objetivo geral de se promover o conjunto de ações de formação ofertado. Seria relevante o registro, de modo público, dos objetivos e das expectativas da EFAP em relação às ofertas de ações de formação, de possíveis trilhas formativas dos educadores para seu desenvolvimento profissional e a relevância dessas ações à prática dos profissionais.

Conforme destacado por Sacristán (1995), outras questão que emerge desse estudo, é quais foram as decisões prévias acerca da oferta dessas ações, como se 
vinculam a forma das ações com a vida interna desses espaços formativos e os conteúdos de ensino com o mundo exterior e, principalmente, com a prática educativa dos educadores, as práticas de avaliação e a reflexão acerca da própria ação? Neste estudo, também não foi possível identificar as respostas às questões destacadas por Tyler (1978), tais como: quais as finalidades da formação continuada? Como são selecionadas e definidas as situações de aprendizagem para alcançar estas finalidades? Como podem ser organizadas as situações de aprendizagem para uma formação continuada eficaz? Como se pode avaliar a eficácia das experiências de aprendizagem?

Pôde ser observado que um conjunto significativo das ações de formação ofertado pela EFAP é relacionado ao Currículo do Estado de São Paulo articulado à prática dos educadores e, então, suscita uma série de outras questões relevantes destacadas por Davis (2011): que currículo estadual é esse? O que o educador tem que aprender? O que ele aprende na formação inicial? Qual o currículo da formação inicial? Porque ele não teve contato com o currículo estadual na formação inicial e precisa retomá-lo na formação continuada com tanta ênfase e de modo compensatório?

Assim, esse estudo aponta a relevância de se ter mais clareza quanto ao planejamento, objetivos e expectativas em relação às ações de formação ofertadas pela EFAP, destacando a formação continuada como um processo contínuo, visando fortalecer a comunidade escolar e o aprimoramento da qualidade da educação, consideradas as necessidades de todos os sujeitos envolvidos nesse processo.

\subsection{Avaliação da oferta de formação continuada}

A sistematização, a execução e a avaliação das ofertas de ações de formação compõem outro ponto a ser considerado. A par dos numerosos documentos e informações sobre a maioria das ações de formação realizadas pela EFAP, seria pertinente a apresentação pública de relatórios qualitativos e quantitativos sobre estas ações, de modo a contribuir com a análise do possível impacto que têm na educação estadual. Nesse sentido, é necessário compreender metodologias de avaliação de programas e de políticas públicas, considerados o planejamento e o resultado. Sendo de fundamental importância considerar indicadores, externos e internos à SEE-SP, inclusive junto à comunidade escolar. Com base nas avaliações dos cursistas e nas avaliações externas e internas à SEE-SP, seria possível à EFAP mensurar - considerados todos os demais indicadores e variáveis - os possíveis impactos das ações de formação na qualidade da educação estadual, objetivo primevo da SEE-SP.

Como uma segunda contribuição, fica a recomendação para que haja dados públicos de avaliação das ações de formação, relatórios periódicos de participantes e resultados alcançados, bem como avaliação de possíveis impactos da formação continuada dos educadores - consideradas as avaliações internas e externas à SEE-SP -, tanto em relação à qualidade da educação quanto em relação ao desenvolvimento profissional e à carreira do educador.

\subsection{Acesso público às ações de formação}

Outro ponto identificado durante a coleta dos dados foi o acesso restrito ao conteúdo das ações de formação. Como contribuição descolada da temática do estudo, mas não menos relevante, é a sugestão de que o acesso ao o acervo das ações de formação seja público, 
reiterando a responsabilidade do estado e dos governos de proverem esse acesso como uma forma de promover a distribuição igualitária dos bens culturais produzidos pela humanidade, rompendo e minimizando as barreiras da divisão social, disponibilizando ao povo o que lhe é de direito [Franco 2009]. Assim, a realização das ações de formação e certificações se dariam no âmbito da SEE-SP, direcionada aos servidores, mas os conteúdos das ações seriam abertos, promovendo o acesso público a esse acervo.

Assim, foi identificado nesse estudo que as políticas públicas de formação continuada de educadores estão sendo colocadas em prática em uma escola de governo em prol de uma educação de qualidade; que as ações ofertadas pela EFAP são orientadas, conforme destaca Davis (2011), basicamente por duas perspectivas, a primeira delas, "individualizada", centra-se na pessoa do professor, buscando valorizálo, e a segunda perspectiva é a colaborativa, promovendo a troca entre pares e a formação em rede; e as TDIC estão sendo apropriadas não só como meio para realização de ações de formação, mas, também, como aparato humano, direito de todos, uma vez que são utilizadas para a democratização do acesso à formação continuada de grande número de profissionais em exercício, integradas ao currículo e podem, então, ser apropriadas à prática pedagógica dos profissionais.

Ainda em relação às TDIC, ao considerá-las fruto do trabalho humano, destacase o acesso dos educadores a essa tecnologia. Reiterando que, conforme Almeida (2009) destaca, a luta para apropriar-se das tecnologias é um amplo espaço das políticas educacionais e pôde-se observar nesse estudo que as TDIC estão amplamente presentes nas ofertas das ações de formação continuada da EFAP.

Todos os aspectos destacados nesse artigo foram identificados nos dados coletados das ações de formação ofertadas pela EFAP, com destaque às que privilegiaram a formação dos educadores para a implementação do Currículo do Estado de São Paulo, compondo uma série de análises convergentes entre a prática da EFAP e as políticas públicas de formação continuada de educadores, bem como destacando algumas fragilidades e suscitando novas questões a serem aprofundadas oportunamente. Nesse contexto, Gatti e Barreto (2009) afirmam que não há receitas para a proposição e execução de ações de formação continuada a educadores, e indicam que os ingredientes fundamentais estão dados: atenção ao contexto social e cultural do professor, condições de trabalho, valorização profissional e gestão com acento na participação democrática e nas responsabilidades das equipes dirigentes da administração central e intermediária, aos quais se poderia acrescentar o fator de políticas integradas e sustentáveis.

Por fim, o sentido ético e a dimensão política do trabalho do educador constituem os pilares da identidade desses sujeitos - acreditar no projeto da educação e acreditar na capacidade dos educandos -, constituindo, assim, a base da proposição das ações de formação continuada de educadores e consideradas suas três dimensões [Almeida e Costa 2011], a política, a pedagógica e a tecnológica.

\section{Referências Bibliográficas}

ALMEIDA, F. J. (2009), "Paulo Freire”. Coleção Folha Explica. São Paulo: Publifolha. e COSTA, V. L. C. (Org.). (2011), "Quantidade é qualidade”. São Paulo: Fundação Padre Anchieta. 
CBIE-LACLO 2015

Anais do XXI Workshop de Informática na Escola (WIE 2015)

BRASIL. (1996), Lei No 9.394, de 20 de dezembro de 1996. "Lei de Diretrizes e Bases da Educação Nacional”. Diário Oficial da União. Brasília, DF.

(2002), Resolução CNE/CP 1, de 18 de fevereiro de 2002. "Diretrizes Curriculares Nacionais para a Formação de Professores da Educação Básica". Diário Oficial da União. Brasília, DF, Seção 1, p. 8.

(2013), Decreto $n^{0}$ 6.755, de 29 de janeiro de 2009. "Política Nacional de Formação de Profissionais do Magistério da Educação Básica”. Casa Civil. Brasília, DF.

(2013), "Diretrizes Curriculares Nacionais da Educação Básica". Brasília: MEC, SEB, DICEI.

. (2014), "Plano Nacional de Educação". Lei no 13.005, de 25 de junho de 2014. Casa Civil. Brasilia, DF.

DAVIS, C. L. F. (et cols). (2011), "Formação continuada de professores: uma análise das modalidades e das práticas em estados e municípios brasileiros", In: Fundação Victor Civita: Estudos e Pesquisas Educacionais. São Paulo: Fundação Victor Civita.

FORQUIN, J. C. (1996), “As abordagens sociológicas do currículo: orientações teóricas e perspectivas de pesquisa". Porto Alegre: Educação e Realidade, v. 21, n. 1.

FRANCO, M. G. A. (2009), “Apropriação das tecnologias da informação e comunicação por jovens e adultos não alfabetizados: um direito humano a ser garantido". São Paulo: PUC-SP.

GATTI, B. A. e BARRETO, E. S. (2009), "Professores do Brasil: impasses e desafios". Brasília: UNESCO.

PANZANI, A. (2014) "Formação continuada de educadores em escolas de governo: conceitos e práticas do Estado de São Paulo". São Paulo: PUC-SP.

SACRISTÁN, J. G. (1995), "Currículo e diversidade cultural”, In: SILVA, T. T.; MOREIRA, A. F. (Orgs.). Territórios contestados: o currículo e os novos mapas políticos e culturais. Petrópolis: Vozes.

SÃO PAULO (Estado). (2009), Decreto n ${ }^{\circ}$ 54.297, de 5 de maio de 2009. Cria a Escola de Formação e Aperfeiçoamento dos Professores do Estado de São Paulo e dá outras providências. . (2010), Currículo do Estado de São Paulo. São Paulo: SEE-SP.

(2010), Decreto $\mathrm{n}^{\mathrm{o}}$ 55.717, de 19 de abril de 2010. Organiza a Escola de Formação e Aperfeiçoamento dos Professores do Estado de São Paulo e dá providências correlatas.

. (2010), Decreto $n^{\circ} 56.460$, de 30 de novembro de 2010. Aprova o Regimento Interno da Escola de Formação e Aperfeiçoamento dos Professores do Estado de São Paulo - EFAP e dá providências correlatas.

TEDESCO, J.C. (2012), “Qualidade da educação e políticas educacionais”. Brasília: Liber Livro.

TYLER, R. (1978), "Princípios básicos de currículo e ensino”. Porto Alegre: Ed. Globo. 